\title{
A new composite decision support framework for strategic and sustainable transport appraisals
}

\section{Barfod, Michael Bruhn; Salling, Kim Bang}

Published in:

Transportation Research. Part A: Policy \& Practice

Link to article, DOI:

10.1016/j.tra.2014.12.001

Publication date:

2015

Document Version

Peer reviewed version

Link back to DTU Orbit

Citation (APA):

Barfod, M. B., \& Salling, K. B. (2015). A new composite decision support framework for strategic and sustainable transport appraisals. Transportation Research. Part A: Policy \& Practice, 72, 1-15.

https://doi.org/10.1016/j.tra.2014.12.001

\section{General rights}

Copyright and moral rights for the publications made accessible in the public portal are retained by the authors and/or other copyright owners and it is a condition of accessing publications that users recognise and abide by the legal requirements associated with these rights.

- Users may download and print one copy of any publication from the public portal for the purpose of private study or research.

- You may not further distribute the material or use it for any profit-making activity or commercial gain

- You may freely distribute the URL identifying the publication in the public portal

If you believe that this document breaches copyright please contact us providing details, and we will remove access to the work immediately and investigate your claim. 


\title{
A NEW COMPOSITE DECISION SUPPORT FRAMEWORK FOR STRATEGIC AND SUSTAINABLE TRANSPORT APPRAISALS
}

\author{
Michael Bruhn Barfod ${ }^{1, *}$, Kim Bang Salling** \\ *Department of Transport, Bygningstorvet 115, Technical University of Denmark, DK - 2800 \\ Kongens Lyngby, Denmark
}

\begin{abstract}
This paper concerns the development of a new decision support framework for the appraisal of transport infrastructure projects. In such appraisals there will often be a need for including both conventional transport impacts as well as criteria of a more strategic and/or sustainable character. The proposed framework is based on the use of cost-benefit analysis featuring feasibility risk assessment in combination with multi-criteria decision analysis and is supported by the concept of decision conferencing. The framework is applied for a transport related case study dealing with the complex decision problem of determining the most attractive alternative for a new fixed link between Denmark and Sweden - the so-called HH-connection. Applying the framework to the case study made it possible to address the decision problem from an economic, a strategic, and a sustainable point of view simultaneously. The outcome of the case study demonstrates the decision making framework as a valuable decision support system (DSS), and it is concluded that appraisals of transport projects can be effectively supported by the use of the DSS. Finally, perspectives of the future modelling work are given.
\end{abstract}

Keywords: Transport appraisal, decision support systems, multi-criteria decision analysis, costbenefit analysis, feasibility risk assessment.

\footnotetext{
${ }^{1}$ Corresponding author. Tel.: +45 4525 1540. E-mail address: mbb@transport.dtu.dk.
} 


\section{INTRODUCTION}

Addressing sustainability issues is a topic of growing concern when performing appraisals of transport infrastructure projects. In this context a sustainable appraisal is defined as one taking into account the widely known three dimensions of sustainability namely the economic, the social, and the environmental dimensions. Incorporation of the concept of sustainability necessitates the revision of traditional decision making processes, where the generally acknowledged cost-benefit analysis (CBA) is used for systematic quantification and comparison of the various benefits and costs generated by a project (Banister and Berechman, 2000; Leleur, 2000). However, decision making based on CBA is found to be inadequate to incorporate and assess multiple, often conflicting objectives, criteria or attributes like environmental or social issues which are usually intrinsically difficult to quantify (Beukers et al., 2012; Barfod et al., 2011; Mackie and Preston, 1998). For this reason it is necessary to expand the decision making process beyond the consideration of solely economic factors (Barfod, 2012a; Wright et al., 2009; Van Exel et al., 2002). The implementation of such a decision making framework under the multiple criteria will require multi-disciplinary and multi-participatory approaches, especially when there is need for assessing a decision problem from different perspectives such as a sustainability perspective (Banister, 2008).

The methodology of multi-criteria decision analysis (MCDA) has previously been used within transport planning to overcome the above mentioned issue of assessing criteria of a strategic character (Barfod, 2012b; Tsamboulas, 2007; Tsamboulas and Mikroudis, 2006; Janic, 2003; Sayers et al., 2003; Vreeker et al., 2002). MCDA, which is based on value measurement using qualitative input from decision-makers, is a widely used methodology for assessing impacts that cannot (or only with difficulties) be assigned with a monetary value or quantified (Edwards et al., 2007; Belton and Stewart, 2002; Keeney and Raiffa, 1993). However, the CBA is a fixed part of infrastructure project evaluations in most countries (Hayashi and Morisugi, 2000; Leleur, 2000). It is therefore necessary to develop a methodology that can comprise both the CBA part

and the MCDA part of an evaluation, and present a composite result based on these. Several such attempts have been made through the recent years, and the following only represents a few attempts relevant in this context. The EUNET (2001) approach incorporated the CBA result in terms of a benefit-cost rate (BCR) or net present value (NPV) as an additional criterion in the 
MCDA, and thereby presented the composite result as relative weight scores. Later the COSIMA approach (Barfod et al., 2011; Salling et al., 2007) made an attempt to 'translate' the MCDA result into CBA 'language' by assigning shadow prices to the criteria, and thereby presented the composite result as total rates of attractiveness. However, the COSIMA approach has later proven difficult to apply in practise due the trade-off considerations that need to be made between the CBA and MCDA parts in order to estimate the shadow prices. More recently an application with some similarities to the EUNET approach - based on including the CBA as an additional criterion in the MCDA - has been made to support the effective implementation of transport policy when prioritising national road infrastructure programmes (Gühnemann et al., 2012).

In this paper a modelling framework is developed taking its basis in the EUNET approach. The framework, however, enhances the CBA-part by introducing the use of feasibility risk assessment (FRA) on the results (Salling and Banister, 2009; Salling, 2008). The scope of the FRA is on the risk that the investment is underestimated and the demand is overestimated which ultimately will produce infeasible economic results. The framework proceeds by examining FRA for the project alternatives one by one, and afterwards the results are used as input as one of the criteria within a set of decision criteria for a MCDA. This way the application of the framework leads to a ranking of the alternatives in order of attractiveness.

Conventional CBA relies on single result values, where all the considerations and calculations are reduced to a single aggregated value such as a NPV or BCR. FRA therefore builds upon the conventional CBA through the adoption of a quantitative risk analysis. Here the probabilities of occurrence of particular risk factors can be incorporated, and decision-makers and analysts can make use of their expertise. The technique used is Monte Carlo simulation which involves a random sampling method (in this case in terms of a Latin Hypercube sampling approach) concerning each different probability distribution selected for the actual model set-up (Vose, 2008). Evidently, input variables such as construction cost estimates, travel time savings, air pollution, accidents savings, etc., are assessed based on various impact, cost and demand models. Current research has however proved that substantial bias and inaccuracy are present within especially two of the input variables, namely the construction costs and demand forecasts which ultimately makes up for the travel time savings (Flyvbjerg et al., 2003, Nicolaisen, 2012). 
Typically four causes with regard to the inaccuracy present in the construction cost and demand forecast are given, capturing technical, economic, political and psychological aspects (Cantarelli et al., 2010; Flyvbjerg, 2007). The technical explanation is defined as so-called forecasting errors which can be boiled down to the fact that models per definition are imprecise.

Furthermore, the second cause is rooted in terms of economic incentives which can lead to deliberate under- or overestimations. Thirdly, there are the political explanations which are more strategic misrepresentations denoted as pessimism bias (Næss et al., 2006) and finally, there are the most well discussed cause namely the psychological explanations which are rooted in planning fallacy and optimism bias. Recently, a fifth category of explanation for bias in project evaluation has been referred to as so-called selection bias claiming that such bias inevitably occurs whenever ex-ante predictions are related to the decisions on whether to implement a project or not (Eliasson and Fosgerau, 2013).

In order to assess such inaccuracy, Flyvbjerg and COWI (2004) constructed a set of references classes which is a pool of projects similar in scope, size, mode, etc. Such reference class information has been gathered within a large database system containing ex-ante and ex-post information with regard to construction cost and demand forecast inaccuracy. Reference Class Forecasting (RCF) was originally developed to compensate for the type of cognitive bias in human forecasting that Princeton psychologist Daniel Kahneman found in his Nobel prizewinning work on bias in economic forecasting (Kahneman and Tversky, 1979). Evidently, each reference class contains information to be fitted against a probability distribution function entailing information for respectively construction cost over-run and demand forecast under-run, so-called Optimism Bias (Salling and Banister, 2009). From such elaboration of uncertainties an accumulated descending output graph can be derived. This type of graph depicts e.g. the BCR in terms of an interval result instead of the conventional single point estimates.

The framework is developed as a part of the Oresund EcoMobility project, which was a part of EU's Interreg IV A programme. The project is a Swedish-Danish cross-border initiative that unites universities, companies and authorities in an effort to increase competence within climate friendly transport of both goods and people. The EcoMobility (EM) modelling framework thus consists of two parts, namely an Excel-based software model (entitled the EM-DSS) and a customised examination process. In the EM-DSS the conventional CBA calculations as well as 
the FRA is carried out. Moreover, the DSS contains a toolbox of different MCDA techniques, which can be used depending on the type of decision problem and the composition of the ratifying group doing the assessments. The concept of decision conferencing (Phillips, 2007) is introduced in the examination process in order to formalise and operationalise the group processes that enable the assessments in the DSS. For illustration, the application of the model is presented by a case study considering alternatives for a new fixed link between Helsingør (Elsinore) in Denmark and Helsingborg in Sweden (referred to as the HH-connection).

The paper is organised as follows. After this introduction the principles for the EM-framework is presented. Following, the case study regarding the appraisal of the HH-connection case is presented and the EM-DSS is applied in terms of a comprehensive assessment by incorporating respectively a feasibility risk assessment including CBA and a MCDA leading to a composite result. Finally, conclusions are made and perspectives for the future modelling work are given.

\section{THE EM MODELLING FRAMEWORK}

The purpose of the EM-framework is to assist the decision-makers in assessing complex decision problems, which usually involve multiple and often conflicting objectives. Focus is on allowing for stakeholder involvement in the process in order to obtain informed and transparent decision support. This part is suggested to be handled using a decision conference approach such as recommended by Phillips $(1984,2007)$ and previously applied to transport planning situations by Barfod (2012a). As mentioned the framework consists of two parts, namely the EM-DSS (an Excel based software model) and an examination process that can be customised to the specific decision situation. Figure 1 depicts how the two parts interact under the framework. The Excel based model featuring the three modules of cost-benefit analysis (CBA), feasibility risk assessment (FRA) and multi-criteria decision analysis (MCDA) makes use of input generated by the examination process, which is organised into five steps of the decision conference (the latter will be described in Section 2.2). 


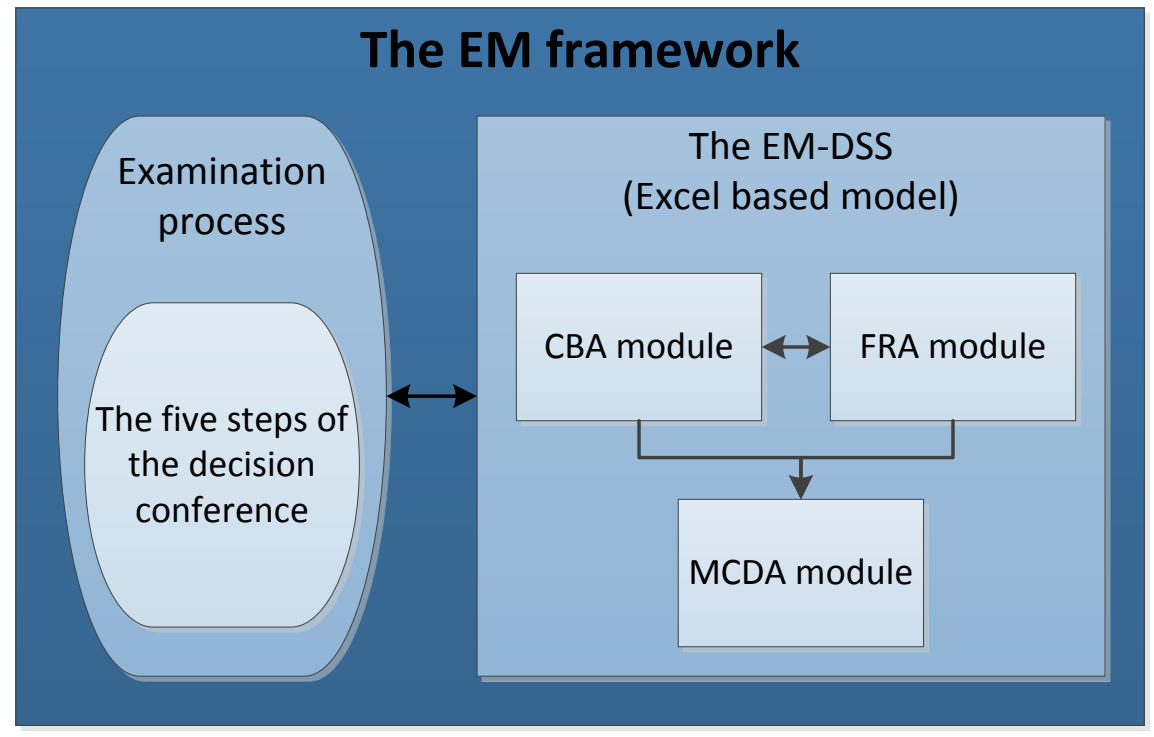

[Figure 1. The EM framework consisting of the examination process and the DSS]

The following sub-sections first introduce the modules of the EM-DSS and next the examination process to be applied when using the EM-DSS.

\subsection{The EM-DSS}

The EM-DSS consists of the three modules: CBA, FRA and MCDA, as depicted in Figure 1. CBA is traditionally a part of any transport project appraisal, and can be conducted in accordance with a national manual securing transparency in the appraisal (Leleur, 2000). However, the CBA does not account for uncertainties in demand forecasts and estimations of construction costs (the two largest impacts for transport projects). Sensitivity analyses has been carried out for many years to map the uncertainty and test the robustness of the CBA results, however, conventional sensitivity analyses do not indicate the probability of occurrence of the scenarios examined. Salling (2008) suggested applying risk analysis using Monte Carlo simulation to the CBA in order to add an extra dimension to the analysis in terms of the likelihood for feasibility. This risk analysis is handled by the FRA module in the EM-DSS. Thus the CBA and FRA modules generate input to the MCDA module of the DSS, which is capable to take into account criteria of also a strategic and sustainable character in addition to the traditional economic impacts. In contradiction to the CBA and FRA modules the MCDA module is dependent on input from decision-makers and stakeholders to assess the criteria and include them in the comprehensive appraisal. The three modules of the DSS are described in the following sub-sections. 


\subsubsection{The CBA module}

The proposed DSS builds on conventional CBA where the costs and benefits of a transport project are considered in a unified framework, so that decision-makers can be informed about the social desirability of the project. However, current research have revealed substantial degrees of uncertainties and bias within the CBA approach in terms of inaccuracy in the determination of the demand forecasts and construction cost estimates, uncertainty in the unit prices and finally the lack of implementation of non-monetary strategic impacts, see Figure 2.

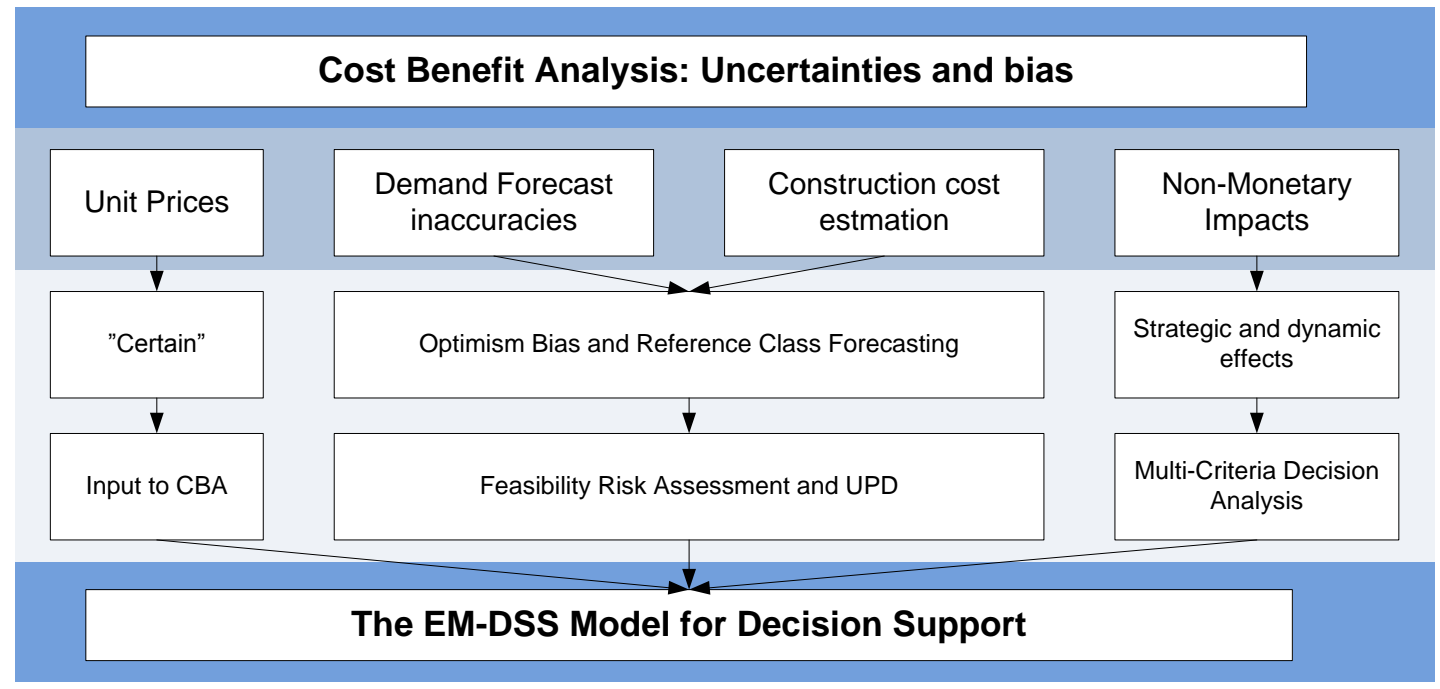

[Figure 2. Overview of the four uncertainties and bias' within CBA]

Evidently, as presented in Figure 2, the CBA as discussed allows for conventional single point output estimates such as net present values, benefit cost ratios etc. Conventionally, a set of standard sensitivity tests are constructed, e.g. upon the discount ratio, growth in GDP etc. However, as part of the Optimism Bias and reference class forecasting (RCF) a set of uplift factors are aligned to include the inaccuracy present within the construction cost estimation. Uplift factors are based on the RCF methodology where percentage uplifts are calculated as presented in Table 1. 


\begin{tabular}{|l|c|c|c|c|c|}
\hline Level of acceptable optimism bias & $\mathbf{5 0 \%}$ & $\mathbf{6 0 \%}$ & $\mathbf{7 0 \%}$ & $\mathbf{8 0 \%}$ & $\mathbf{9 0 \%}$ \\
\hline Road & $15 \%$ & $24 \%$ & $27 \%$ & $32 \%$ & $45 \%$ \\
\hline Rail & $40 \%$ & $45 \%$ & $51 \%$ & $57 \%$ & $68 \%$ \\
\hline Fixed links & $23 \%$ & $26 \%$ & $34 \%$ & $55 \%$ & $83 \%$ \\
\hline
\end{tabular}

[Table 1. Applicable capital expenditure uplifts for selected percentiles applied to constant prices (adapted from (Flyvbjerg and COWI, 2004))]

Generally, the point is to include a level of acceptable inaccuracy within the construction cost estimates i.e. an $80 \%$ acceptance level corresponds to a $32 \%$ increase of the construction cost for a road type project etc. Such tests have been conducted for a long period of time, however, the fact remains that this merely shifts the BCR or NPV deterministically producing new single point values to the decision-makers.

Accordingly, Table 1 is derived based upon RCF information, thus, this paper suggest to include the probability distributions which basically are the foundation for the uplift values presented. Thus, a large scale database has been collected in the period from 2009 until 2013 containing information in this regard (Nicolaisen, 2012). The unit prices are in this modelling scheme assumed fixed which entails that it is only the first year impact related to the demand and construction cost to be included in the CBA that are treated in the further. Finally as described previously, a new set of entries are taken into account, namely the non-monetary impacts such as strategic, dynamic and sustainable of nature. Such impacts are normally not included within the CBA.

\subsubsection{The FRA module}

In the CBA module a set of deterministic NPVs or BCRs for each alternative are determined in accordance with a national manual for socio-economic appraisal of transport projects (Danish Ministry of Transport, 2003). Correspondingly, the embedded uncertainties are treated through stochastic calculations where a set of reference classes respectively for railway and fixed link projects are collected as reference classes. The database system used in the EM-DSS (the UNITE Project Database - UPD) contains almost 200 transport projects with information with regard to input data to the FRA and Monte Carlo simulation in terms of selecting an appropriate 
probability distribution (Nicolaisen, 2012). The UPD has been initialised as a consequence to the increasing demand for informed and risk-based decision support within transport infrastructure appraisal. The general idea is to gather all possible and available information regarding implemented transport investment projects in Scandinavia and other Western Europe countries, which can be used as frame of reference for any future evaluations. Moreover, the UPD is subdivided into a set of various indicators which allows to specify the sample of corresponding projects, see Figure 3.

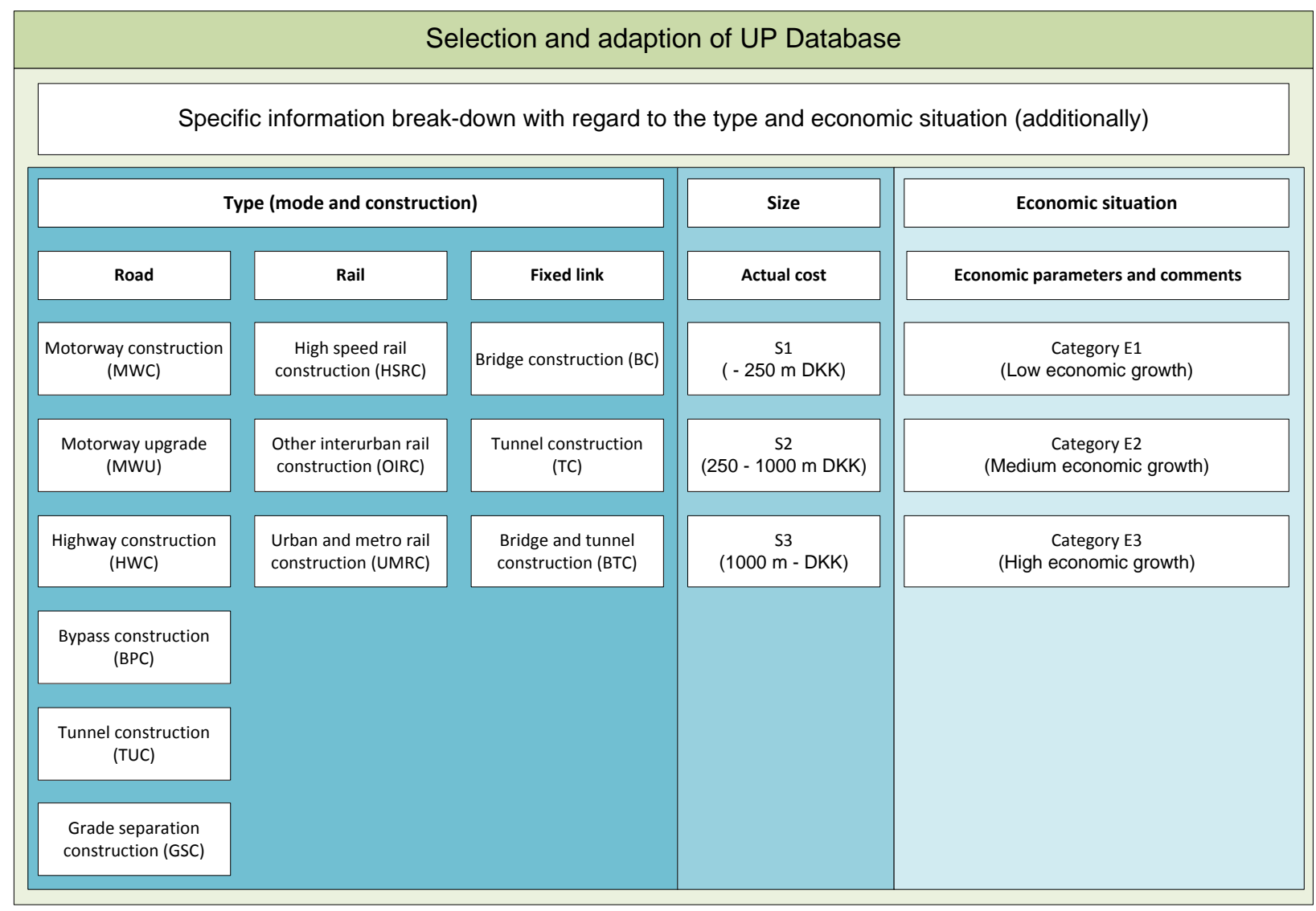

[Figure 3. Selection and adaption of the UP Database.]

Thus, a set of reference classes respectively for fixed links and rail projects (that have been associated with various types of large scale transport projects such as tunnels etc.) are collected and pooled to produce the input probability distribution to the forthcoming feasibility risk assessment procedure, as depicted in Figures 4 and 5. 


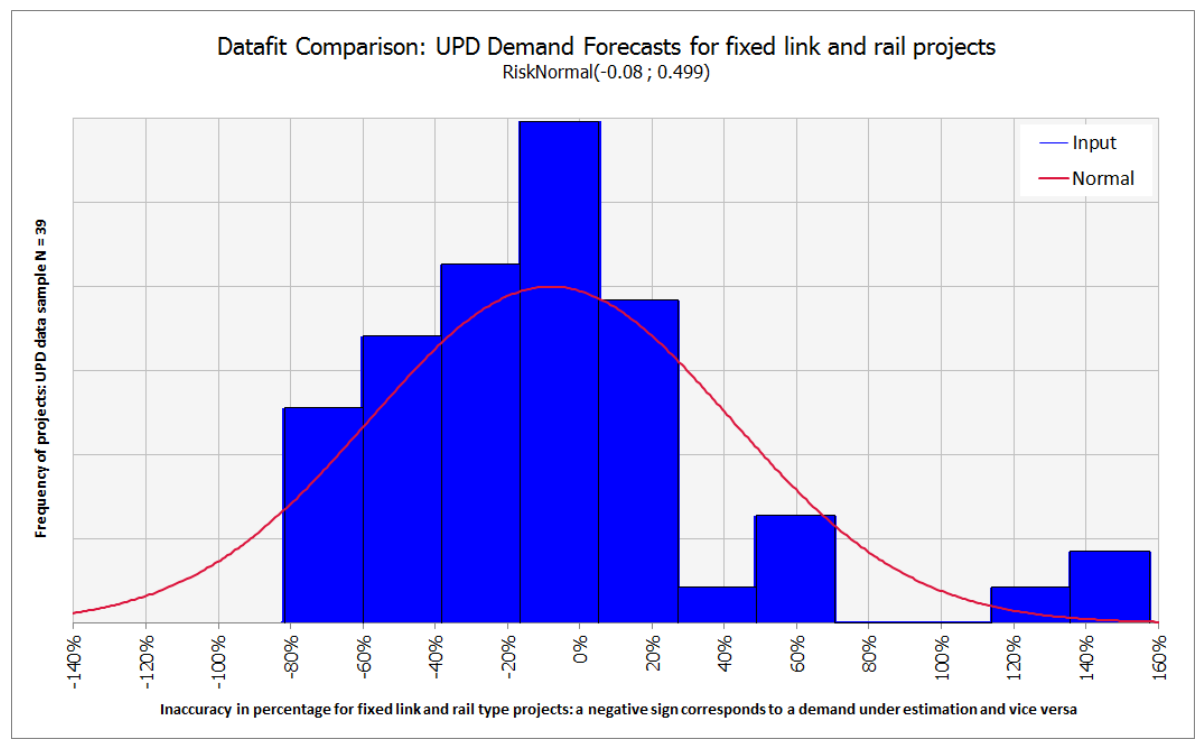

[Figure 4. Inaccuracies of demand forecasts for fixed link and rail projects containing altogether 39 projects (average $-10.4 \%$ ). Inaccuracy is measured as actual minus forecast traffic in percentage of forecast traffic, thus, a negative sign refers to lower actual demand than predicted and vice versa (Nicolaisen, 2012).]

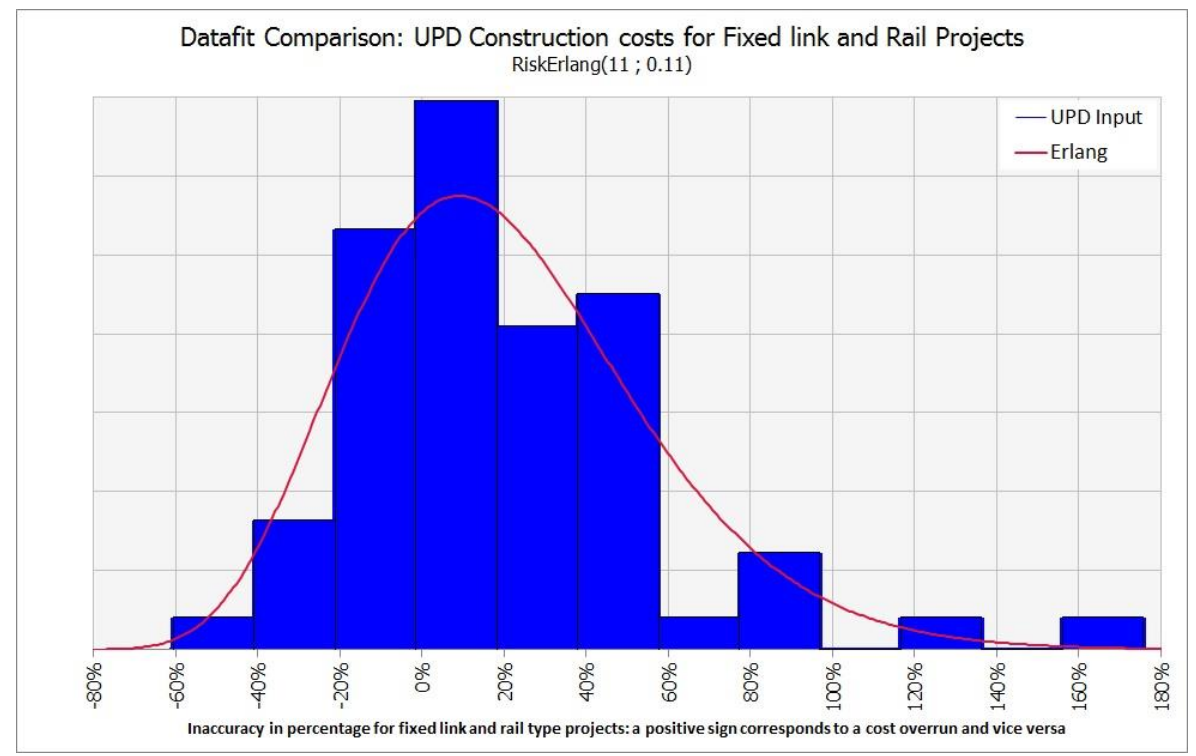

[Figure 5. Inaccuracies of cost estimates for fixed link and rail projects containing altogether 62 projects (average 20.4\%). The figure show the percentage distribution of projects with respect to cost over/under-run (constant prices), thus, a positive sign refers to estimated costs are underestimated (Nicolaisen, 2012).] 
The two sets of data fit illustrated in Figure 4 and Figure 5 both support the underpinning theory of Optimism Bias where demand forecasts typically are overestimated (thus producing more travellers than actually is the case) and the construction costs are underestimated (hence producing higher costs than originally estimated - and more crucial used within the decision basis). The two sets of distributions produced, respectively in terms of the Erlang distribution for construction costs and Normal distribution for the demand estimates are assigned each individual impact within the CBA and simulated in terms of a Monte Carlo simulation (Salling and Leleur, 2012). Based on these simulations a set of 'certainty graphs' can be produced which indicate the probability of achieving a feasible project. This information can be used as input for the MCDA module of the EM-DSS where it is treated as an additional criterion.

\subsubsection{The MCDA module}

The MCDA module of the EM-DSS is capable of assessing those criteria that are not addressed by the CBA and FRA but still holds a potential of improving the decision support. These criteria can - as mentioned earlier - be of a strategic, dynamic or sustainable character. Determining which criteria that are relevant to include in the appraisal is a very important part of the process and should be handled with care as it has a high effect on the final result. Section 2.2 which deals with the examination process will elaborate on this issue.

The EM-DSS follows an approach similar to the EUNET (2001) approach, where the CBA result is added as an additional criterion and treated in line with the other criteria in the MCDA. The new feature of the EM-DSS is that instead of using e.g. BCRs as input, the certainty graphs from the feasibility risk assessment (mentioned in the last paragraph of section 2.1.2) is presented to the ratifying group (i.e. the decision-makers and stakeholders participating the decision conference), and the assessment of the criterion is made based on these graphs. Hence, the risks and uncertainties will also be taken into account in the comprehensive appraisal.

Before commencing the interaction process with the ratifying group it is, however, necessary to select a specific analytical approach. This model building can be regarded as a dynamic process which interacts with the process of the appraisal. The nature of the analytic approach which is selected will differ according to the nature of the assessment and the definition of the alternatives (Belton and Stewart, 2002). Moreover, the composition of the ratifying group using the approach 
should also be considered: are we dealing with professionals/experts or persons with only a superficial knowledge about the decision problem? The task of selecting an assessment technique might very well lead to the realisation that one technique is not sufficient to meet the requirements of the decision problem. For this reason a mix of techniques is a potential useful solution. It is most likely when appraising transport projects that different decision situations can occur containing some of the following characteristics:

- The alternatives to be assessed can either be well-defined and easy to measure with regard to potential impacts or they can be poorly defined making them very difficult to assess.

- The criteria to be weighted can either be based on well-defined measureable attributes and easy to weight, or the attributes can be non-measureable making it difficult to interpret the weights.

- The ratifying group can either consist of professionals which are experts within their area and have experience in the type of judgments to be made (expert users), or they can be persons with only a superficial level of knowledge about the issue in hand (basic users).

The different decision situations sketched above set varying requirements to the techniques to be used in the EM-DSS. The following techniques which are included in the MCDA module have previously been found applicable for the types of decision situations mentioned above (Barfod, 2012a). However, it is most likely that other techniques such as e.g. outranking approaches could be appropriate to include in the module as well. The module is for this reason not limited to the techniques mentioned here, and can be expanded in future developments.

- SMART (Simple Multi-Attribute Rating Technique) (Goodwin and Wright, 2009; Von Winterfeldt and Edwards, 1986) is based on the additive value function model and assigns direct scores to alternatives and direct weights to criteria. The technique demands a high level of knowledge about the alternatives/criteria to be assessed in order to be accurate and should for that reason only be used when measureable attributes can be identified for the criteria. Moreover, the technique should only be used by experts or professionals which are experienced users of the technique. 
- The multiplicative AHP (Lootsma, 1992) is based on pair wise comparisons of alternatives and criteria to obtain scores and weights. The technique is a further development of the original additive Analytic Hierarchy Process (AHP) by Saaty (1977) and is based on the multiplicative value function model. The multiplicative AHP offers a more theoretically correct approach than the additive AHP, but in practice the two methods demand the same type of input and generate the same type of output (Olson et al., 1995). Thus the two applications are useful in the same decision situations. A nine point intensity scale of importance is used to express the decision-makers' preference for one object over another. The technique is very simple to use as the problem is decomposed into simple judgments requiring no measurable attributes, and is useful in situations where the alternatives are weakly described and where it is difficult to assign weights to the criteria (Barfod, 2012b). Moreover, the technique has proven its worth in group decision making situations where scores and weights are obtained through discussions.

- Swing weights (Von Winterfeldt and Edwards, 1986) is usually considered to be the theoretical most correct and accurate method for deriving criteria weights, but it is most likely also the most difficult one to use in practice. The technique presupposes that the decision-makers consider the swing from the worst value to the best value within each criterion. If the value tree is small the decision-maker may be asked to consider all criteria simultaneously and assess which swing gives the greatest increase in overall value; this criterion will have the highest weight (Belton and Stewart, 2002). The process is repeated on the remaining criteria until the order of benefit resulting from a swing from worst to best on each criterion has been determined, thereby defining a ranking of the criteria weights. To assign values to the weights the decision-maker must assess the relative value of the swings. In practice the technique is difficult to explain to basic users and should for that reason only be used with care.

- SMARTER (Simple Multi-Attribute Rating Technique Exploiting Ranks) (Goodwin and Wright, 2009) is - as the name implies - a further development of SMART. The technique is very simple in the sense that it only demands the decision-makers to rank the criteria in order of importance after which predetermined surrogate weights are assigned 
to the criteria, e.g. ROD weights which are surrogate weights that are determined on the basis of probability theory (see Roberts and Goodwin (2002) for details). The method presupposes no measurable attributes and is easy accessible and very simple to use for decision-makers which are basic users. Although the weights obtained from this techniques is not as accurate as swing weights they are still a close approximation to such weights (Roberts and Goodwin, 2002), and in practice the difference will be insignificant in most cases.

Based on the above it is clear that different techniques should be used both depending on the alternatives and criteria to be addressed, but also on the persons to apply the techniques in the decision process. As mentioned two main modes are to this respect relevant: a basic-user mode consisting of non-professionals, and an expert-user mode consisting of professional and experienced users of the techniques. Table 2 depicts the techniques included in the MCDA module for use in the two modes.

\begin{tabular}{|c|c|c|}
\hline & Basic user mode & Expert user mode \\
\hline Criteria weights & SMARTER & Swing weights \\
\hline Alternative scores & The multiplicative AHP & SMART / the multiplicative AHP \\
\hline
\end{tabular}

[Table 2. Techniques embedded in the MCDA module to be used when assessing criteria and alternatives respectively. Dependent on user mode different techniques is recommended.]

Basic users should make use of the simplest set-up of techniques as possible in the decision process in order to avoid misunderstandings and misinterpretations. Thus the SMARTER technique can be used for assigning weights to the criteria, as this only requires the users to rank the criteria in order of importance. For assigning scores to the alternatives the basic users should make use of the multiplicative AHP, which only requires them to consider simple pair wise comparisons according to a verbal scale.

Expert users must be considered to be capable of perceiving more demanding methods than the basic users as they often are professionals with much experience in assessment tasks. For this reason the swing weight technique can be applied to determine weights for the criteria, as the technique makes it possible to determine the weights with a relatively high accuracy. For the 
scoring of alternatives the SMART technique should be used if the attributes are measureable, if not the multiplicative AHP should be applied as in the case with the basic users.

Depending on who to perform the assessment, basic users or expert users, and what techniques to apply for the determination of weights and scores there is a risk of achieving conflicting results. As MCDA is based on subjective input this will always be an issue as people have different preferences. It is therefore important to note that the result of a specific assessment only reflects the preferences of the persons/stakeholders that performed it.

The final aggregation of the results is conducted differently depending on the selection of techniques. If the multiplicative AHP is involved a multiplicative aggregation procedure is also applied. If the multiplicative AHP is not among the selected techniques the more simple (understandable) additive aggregation procedure is applied instead. Section 3 will illustrate the final aggregation in details.

Having selected the analytic approach the interaction with the decision-makers and stakeholders can commence. Section 2.2 introduces the examination process that is proposed to structure this interaction in the EM framework.

\subsection{The examination process}

The examination process should always be designed to accommodate the actual infrastructure project to be appraised. The process can be divided into two main phases: the preliminary problem structuring phase and the interaction phase. The preliminary phase takes its point of departure in problem structuring methods where the problem in the first stage is identified by using techniques for focussing on the problem and on the possible alternatives, and doing a problem formulation (see e.g. Barfod (2012b) for details).

In order to structure the interaction phase the concept of decision conferencing is introduced into the framework. It enables a structured debate between the groups that are either involved in and/or affected by the decision problem. The debates, evolving between the groups representing different perspectives on the problem, are able to enrich the basis on which the decisions have to be made. Thus the aim of a decision conference is to develop a common understanding of the decision problem between the groups, to create a sense of common purpose and achieve a 
common group commitment (Phillips and Bana e Costa, 2007). The concept consists of the main components: group processes, decision analysis (creating the structure) and information technology (in the present case the EM-DSS). The group processes are assisted by an impartial facilitator guiding the participants though the steps of the decision conference. As suggested by Barfod (2012a) such a decision conference can be based on a five-step process involving the participants in the decision making process. The five steps are universal and can be applied regardless of the nature of the decision problem considered; only minor adjustments should need to be made within the steps. Figure 6 illustrates the five steps and their input with regard to methodology and their resulting output.

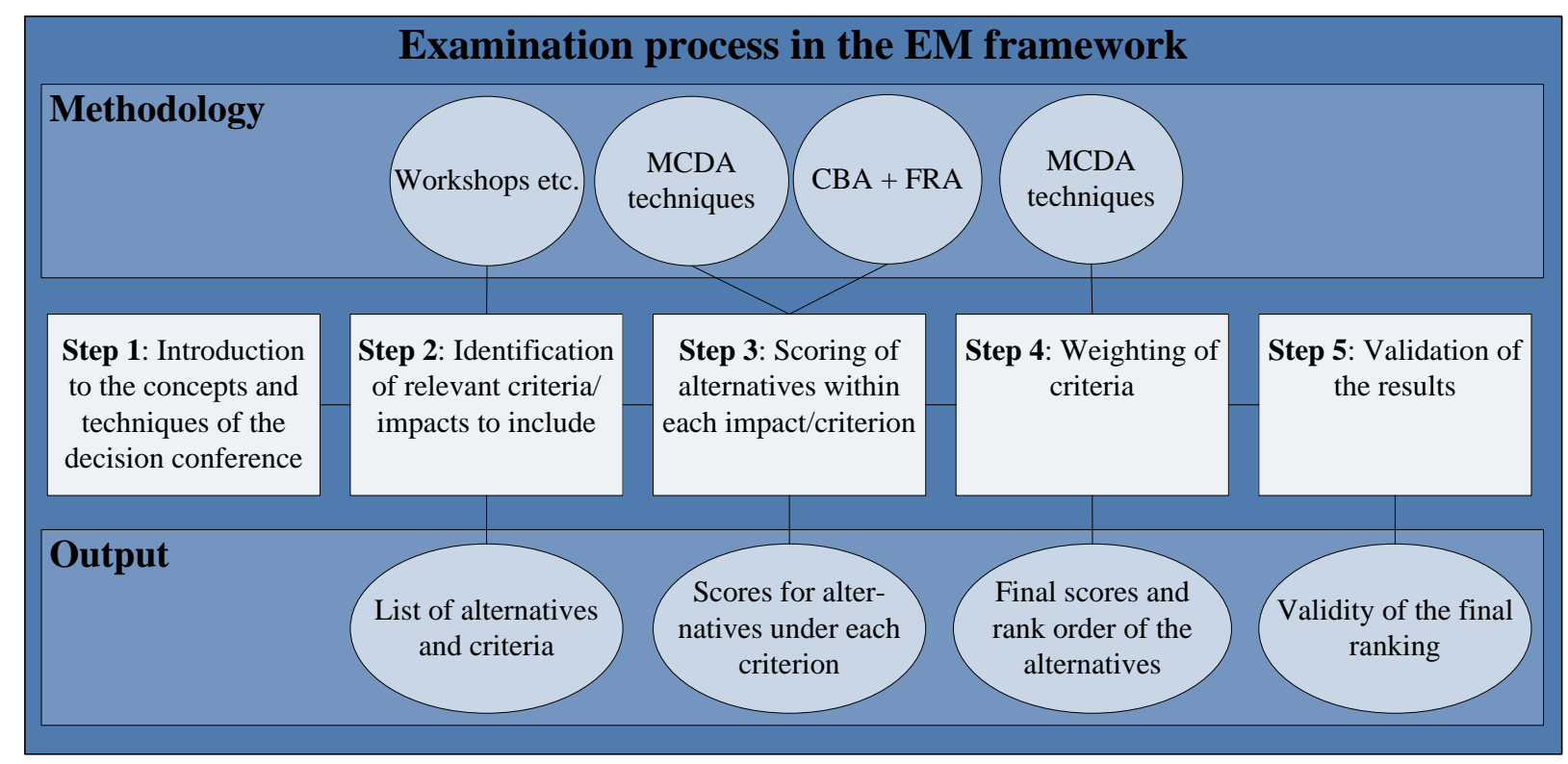

[Figure 6. The examination process proposed for the EM framework]

Step 1 introduces the concepts and methods being used at the specific decision conference in simple terms. This contributes to make the decision-makers feel more comfortable with the later decisions when they know the basic characteristics of the DSS. Step 2 features the identification of relevant impacts for the assessment. In this respect it can be very useful to conduct workshops already in the initial planning phase, where issues regarding the project initiative can be discussed and criteria with influence on the decision making can be developed. In the initial planning phase a lot of criteria will often be generated, hence it is up to the participants at the decision conference to structure and reduce the criteria into a number of relevant criteria which 
are operational and all contribute to the segregation between the alternatives. Once all relevant criteria have been defined Step 3 comprises the scoring of the alternatives. Dependent on the level of knowledge about the alternatives and the criteria to be assessed different MCDA techniques can be applied in order to determine scores (see Section 2.1.3). Step 4 introduces the most subjective part of the appraisal: the weighting of the criteria. This task is considered to be very difficult as very opposite world views (which may be present at the decision conference) will generate different weight sets, and instead of trying to make the participants agree, it can be useful to examine the different weight sets provided by each participant individually. After deriving separate scores for the alternatives and weights for the criteria it is possible to produce a result in Step 5. It should be noted, that if the participants in the decision conference feel unconfident with the results it is possible to go back in the process and, hence, revise the assessments or perhaps test the various weight settings applied. The information about the assessments conducted and the participants' arguments during the decision making process should be documented in an assessment protocol. This can be valuable to review and justify the decision and can be useful if the process is going to be repeated after some time.

If it is not possible for the participants to obtain consensus about one or more judgments during the decision conference this should be recorded in the protocol as different preference (or stakeholder) profiles. These preference profiles can subsequently be treated by the DSS, and the output of the decision conference will be more than one single recommendation. Instead the decision makers will be provided with information about how different preferences can lead to either similar or different results. This information is no matter what very useful for a decision maker when determining the way forward.

\section{APPLICATION OF THE FRAMEWORK}

In the following sub-sections the case study will be presented, and it will be described how the proposed EM framework was applied.

\subsection{The case study}

The Oresund fixed link connecting Copenhagen in Denmark with Malmö in Sweden opened to traffic in 2000 (see Figure 7). The fixed link between Zealand and the rest of Scandinavia has led to a strong increase in traffic across Oresund as a whole. In 2009, an average of 19,500 vehicles 
and 184 trains crossed the link per day, corresponding to $141 \%$ and $125 \%$ increase respectively compared to the first full year of operations in 2001 (Oresundsbro Konsortiet, 2010). Moreover, a fixed link across Fehmarn Belt between Denmark and Germany, which is expected to open in 2021, will increase these numbers due to more travellers from central Europe through Denmark to the rest of Scandinavia (Sweden and Norway). Especially, the number of freight trains through Denmark is expected to grow significantly, turning the Oresund fixed link into a bottleneck, since the existing capacity is already close to the limit.

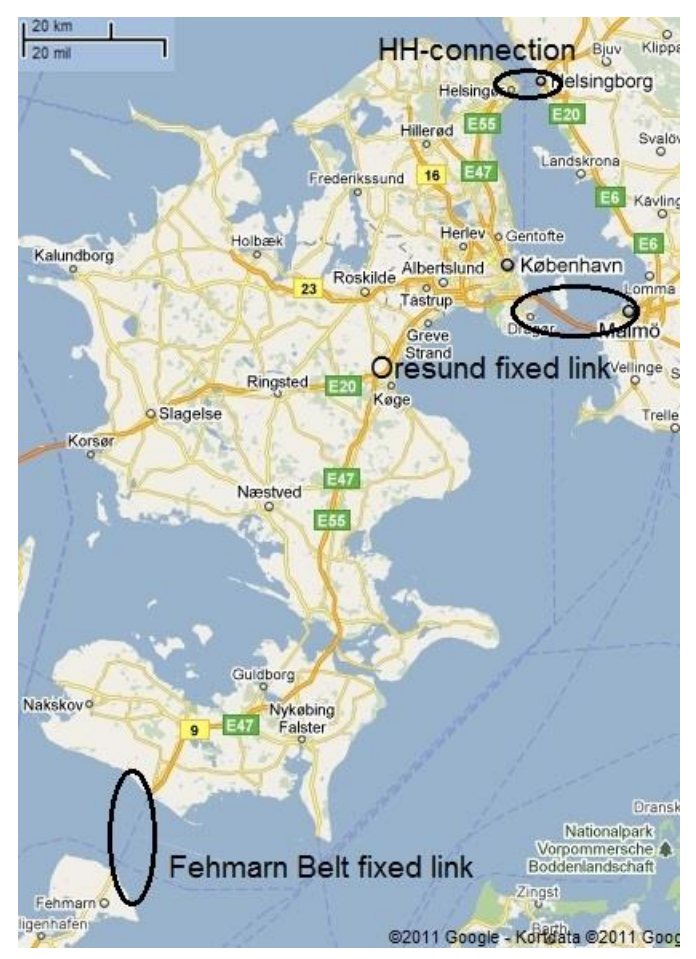

[Figure 7. The proposed new fixed link (HH-connection), the Oresund fixed link and the forthcoming Fehmarn Belt fixed link (from Google maps)]

The proposal of a fixed link between Helsingør (Elsinore) in Denmark and Helsingborg in Sweden - referred to as the HH-connection - has been considered since the 1980s. However, the opening of the Oresund fixed link postponed the planning and implementation. The case is now again relevant in order to cope with the increasing traffic across the Oresund and the planned Fehmarn Belt fixed link (see Figure 7). A new northern fixed link would reduce the travel time between Zealand and the rest of Scandinavia, relieving the Oresund fixed link for some of the car and railway traffic. Three tunnel alternatives identified through a previous study by Larsen and 
Skougaard (2010) were considered as main alternatives for the HH-connection at a decision conference. The alternatives are listed in Table 3 with indication of type of construction, type of traffic and construction costs (in million DKK).

\begin{tabular}{|l|l|l|}
\hline HH-connection & Description & Construction cost \\
& Tunnel for rail $(2$ tracks $)$, passenger trains only. & 9,500 \\
\hline Alt. 1 & $\begin{array}{l}\text { Tunnel for rail }(2 \text { tracks }), \text { passenger trains only }+ \\
\text { tunnel for vehicles }(2 \times 2 \text { lanes }) .\end{array}$ & 24,500 \\
\hline Alt. 3 & $\begin{array}{l}\text { Tunnel for rail }(2 \text { tracks }), \text { passenger trains }+ \text { tunnel for } \\
\text { vehicles }(2 \times 2 \text { lanes })+\text { tunnel for rail (single track), }\end{array}$ & 32,500 \\
\hline
\end{tabular}

[Table 3. The three proposed alternatives for the HH-connection (Larsen and Skougaard, 2010)]

\subsubsection{CBA and FRA calculations}

The CBA and FRA, which is input to Step 3 in the examination process (Figure 6), can with advantage be conducted before commencing the decision conference. These calculations are initially based on traffic model calculations and are in consequence of this rather time consuming to perform.

In accordance with the Danish manual for socio-economic analysis (Danish Ministry of Transport, 2003) the CBA includes estimations of the construction costs, time savings, vehicle operating costs, maintenance and operating cost of the infrastructure, environmental consequences $\left(\mathrm{CO}_{2}\right.$ and local emissions), and ticket revenue. Based on this a set of deterministic BCRs and NPVs for each alternative are determined as depicted in Table 4. The embedded uncertainties are following treated through stochastic calculations where a set of reference classes respectively for railway and fixed link projects are used as described in Section 2.1.2. Based on the FRA simulations a set of certainty graphs are produced as depicted in Figure 8. 


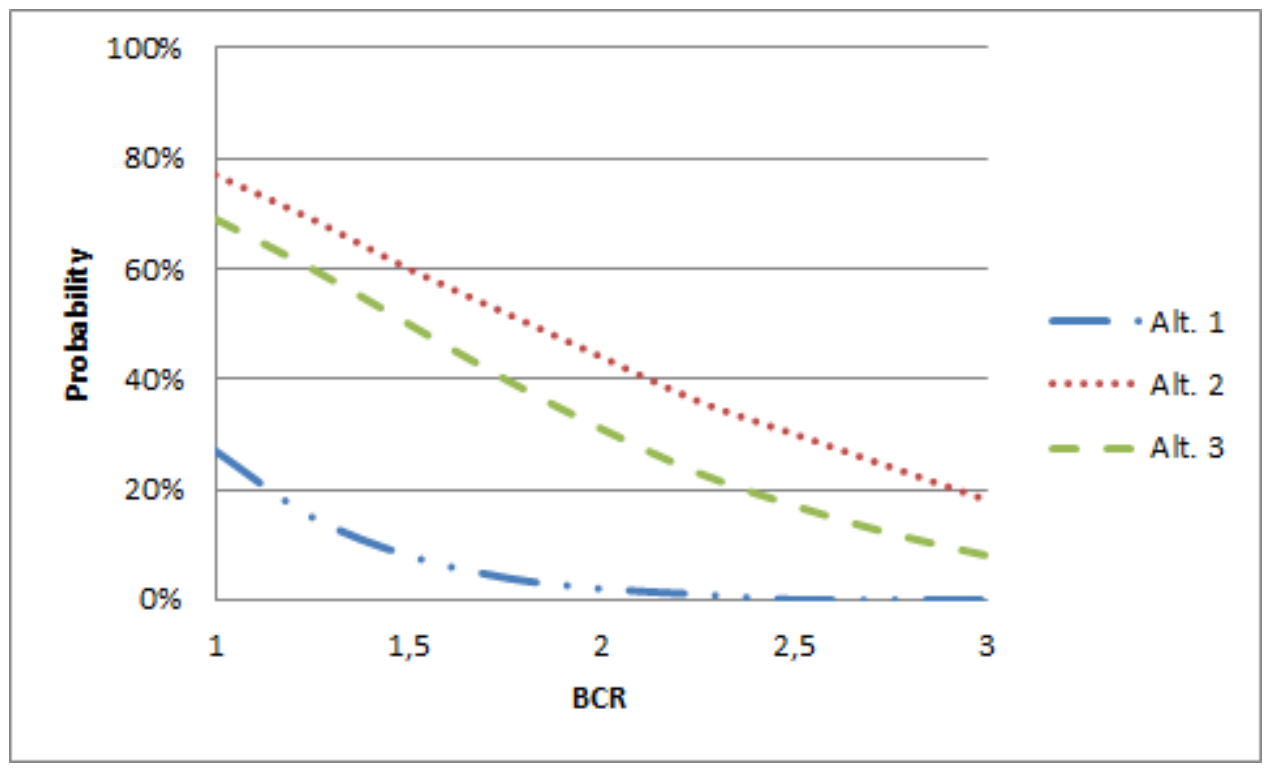

[Figure 8. Certainty graphs for the three alternatives]

The points where the graphs cross the y-axis indicate the probability of achieving a BCR higher than 1, which implies an economic robust alternative. However, none of the alternatives in the case are $100 \%$ certain of being feasible, which indicates that even though the conventional CBA produces feasible results for all three alternatives - the robustness and risk within the CBA returns only certainty of feasible alternatives respectively in $27 \%, 77 \%$ and $69 \%$ of the simulations. The economic criteria along with the calculated certainty values (CV) indicating these probabilities are listed in Table 4.

\begin{tabular}{|l|c|c|c|}
\hline & BCR & NPV (million DKK) & CV \\
\hline Alt. 1 & 1.23 & 2,657 & $27 \%$ \\
\hline Alt. 2 & 2.38 & 40,506 & $77 \%$ \\
\hline Alt. 3 & 1.99 & 38,518 & $69 \%$ \\
\hline
\end{tabular}

[Table 4. Economic decision criteria and certainty values (CV) for the three alternatives]

\subsubsection{Decision criteria}

The overall goal of the case study is to find not only the socio-economically most sound, but also the most sustainable alternative for both passenger and freight transport. Due to the high 
influence on the further development of the Oresund region a wider set of decision criteria have been identified to lay the foundation for a comprehensive assessment of the three alternatives. The decision criteria were selected at the decision conference on the basis of a long list of criteria stemming from a preliminary workshop organised to generate relevant criteria for this specific case problem (see Figure 6). Special care was in this respect made to avoid double counting between the selected criteria and the impacts included in the CBA in order not to measure the same impacts more than once. The workshop was attended by representatives of key stakeholders and focus was on developing criteria that represented all the three pillars of sustainability capturing environmental, social and economic aspects. Table 5 depicts the criteriaset selected, where C1, C4 and C5 stem from the economic pillar, C2 and C3 stem from the social pillar, and finally $\mathrm{C} 6$ stems from the environmental pillar. $\mathrm{C} 1$ is stemming directly from the FRA and thus includes the CBA impacts and their associated uncertainty. Hence C4 and C5, which are also economic criteria, do not include anything already captured by $\mathrm{C} 1$. The same is the case with $\mathrm{C} 2, \mathrm{C} 3$ and C6.

Note that none of the criteria have been divided into sub-criteria, but instead operates at an overall level. Therefore the components of the criteria are not weighed against each other, but assumed to contribute equally to the assessment of the specific criterion. If the participants had felt a need for sub-dividing one or more criteria, e.g. if some components under the criterion were contradicting, then the weighting could be conducted using one of the proposed techniques as well.

\begin{tabular}{|l|l|}
\hline Criterion & Definition \\
\hline C1: Socio-economic & $\begin{array}{l}\text { The criterion embraces the overall economic performance of the } \\
\text { alternative. The main indicator is the CV calculated based on the } \\
\text { results stemming from the CBA and FRA. }\end{array}$ \\
\hline $\begin{array}{l}\text { C2: Improvement for } \\
\text { transponger cars and public }\end{array}$ & $\begin{array}{l}\text { The criterion emphasises the accessibility for both cars and public } \\
\text { transportation. This is represented by the increased mobility } \\
\text { potential that the commuters obtain (they can cover more } \\
\text { geographic space using the same time as previously). }\end{array}$ \\
\hline
\end{tabular}




\begin{tabular}{|c|c|}
\hline $\begin{array}{l}\text { C3: Impact on towns and } \\
\text { land-use }\end{array}$ & $\begin{array}{l}\text { The criterion emphasises the visual environment in the towns of } \\
\text { Elsinore and Helsingborg. The form of the land-based facilities } \\
\text { and their geographical placement will for this reason be in focus. }\end{array}$ \\
\hline $\begin{array}{l}\text { C4: Impact on regional } \\
\text { economics }\end{array}$ & $\begin{array}{l}\text { The criterion considers the alternatives' potential for contributing } \\
\text { to the economic development in the Oresund region. In order to } \\
\text { obtain economic development in the northern part of the Oresund } \\
\text { region the area should become more attractive both to housings } \\
\text { and businesses. }\end{array}$ \\
\hline $\begin{array}{l}\text { C5: Impact on flexibility in } \\
\text { logistics }\end{array}$ & $\begin{array}{l}\text { The criterion covers the impact on the efficiency, punctuality, } \\
\text { security, co-modality and risk in the logistic chains. A new } \\
\text { connection can help to expand companies' clientele, and at best, } \\
\text { it can result in that some companies can close down a production } \\
\text { area, thereby, saving money. }\end{array}$ \\
\hline $\begin{array}{l}\text { C6: Contribution to the EU } \\
\text { green corridors }\end{array}$ & $\begin{array}{l}\text { The criterion emphasises the alternatives' potential for promoting } \\
\text { the green transport corridors which support the EU's agenda } \\
\text { towards decarbonising transport while emphasising the need for } \\
\text { efficient logistics. }\end{array}$ \\
\hline
\end{tabular}

[Table 5. The decision criteria under consideration]

\subsection{The decision conference}

The decision conference was controlled by an impartial facilitator and supported by a model analyst using the EM-DSS to perform on-the-spot modelling of the information obtained from the group. The ratifying group consisted of stakeholders with significant different backgrounds, and were selected based on an initial stakeholder analysis. After the introduction in Step 1 and the selection of decision criteria in Step 2 (see Figure 6), the task for the participants was to score the alternatives under each criterion in Step 3. As the ratifying group mainly consisted of basic users it was in advance decided to use the multiplicative AHP featuring pair wise comparisons for the scoring process (see Table 2). The verbal information from the pair wise comparisons was then converted into numerical values $\left(\delta_{\mathrm{jk}}\right)$ according to the intensity scale going from 0 
(indifference) to 8 (very strong difference) and filled into the comparison matrices of the EMDSS. An example of such a matrix is shown in Table 6 depicting the calculations of the alternatives' scores under the 'socio-economic robustness' criterion. Using the multiplicative AHP the input values, $\delta_{\mathrm{jk}}$, are converted into values on a geometric scale using a progression factor that expresses the perception of going from one verbal statement to another on the difference based scale. This progression factor is set to 2 and the transformations $\left(\mathrm{r}_{\mathrm{jk}}\right)$ of the verbal statements are calculated using $\mathrm{r}_{\mathrm{jk}}=\exp \left(\gamma \delta_{\mathrm{jk}}\right)$, where $\gamma$ is the progression factor and equal to $\ln (2)$. The scores for the alternatives are subsequently calculated by the geometric mean value for each row in the transformed matrix. For more information about the calculations using the multiplicative AHP see e.g. Olson et al. (1995). The certainty graphs illustrated in Figure 8 were used as input for the discussion regarding the socio-economic robustness criterion.

\section{Criterion 1: Socio-economic robustness}

\begin{tabular}{|l|l|l|l|l|l|l|l|l|}
\hline & \multicolumn{2}{|l|}{ Comparisons $\left.\mathbf{(}_{\mathbf{j k}}\right)$} & \multicolumn{2}{l|}{ Transformation $\left.\mathbf{( r}_{\mathbf{j k}}\right)$} & \\
\hline & Alt. 1 & Alt. 2 & Alt. 3 & Alt. 1 & Alt. 2 & Alt. 3 & Score \\
\hline Alt. 1 & $\mathbf{0}$ & -6 & -4 & & 1 & 0.015625 & 0.0625 & $\mathbf{0 . 1 0}$ \\
\hline Alt. 2 & 6 & $\mathbf{0}$ & 3 & 64 & 1 & 8 & $\mathbf{8 . 0 0}$ \\
\hline Alt. 3 & 4 & -3 & $\mathbf{0}$ & 16 & 0.125 & 1 & $\mathbf{1 . 2 6}$ \\
\hline
\end{tabular}

[Table 6. Comparison matrix for the socio-economic robustness criterion]

Table 7 summarises the calculated scores for the alternatives under each of the six criteria.

\begin{tabular}{|l|c|c|c|c|c|c|}
\hline & C1 & C2 & C3 & C4 & C5 & C6 \\
\hline Alt. 1 & 0.10 & 0.02 & 0.02 & 0.06 & 0.02 & 0.10 \\
\hline Alt. 2 & 8.00 & 4.00 & 10.08 & 2.52 & 1.59 & 0.40 \\
\hline Alt. 3 & 1.26 & 10.08 & 4.00 & 6.35 & 25.40 & 25.40 \\
\hline
\end{tabular}

[Table 7. Scores for the alternatives under each criterion]

After the scoring process the criteria weights were to be determined in Step 4. As mentioned before the group mainly consisted of basic users, hence according to Table 2 the SMARTER technique was selected for the purpose. Using this technique the group was asked to rank the 
criteria in order of importance. This ranking was first done individually by each group member, and afterwards the group made an attempt to set up a ranking reflecting a compromised common agreement. In this way both a compromised solution could be presented as well as solutions reflecting each participant's viewpoint. All in all four different rankings were created (\#1 - \#4) together with the common agreed ranking (the compromise), which was based on discussions and trade-offs in the group. The criteria were then assigned with the pre-determined ROD weights according the SMARTER technique. The rankings are depicted in Table 8.

\begin{tabular}{|l|c|c|c|c|c|c|c|c|c|c|}
\hline & \multicolumn{2}{|c|}{ Common } & \multicolumn{2}{|c|}{$\# 1$} & \multicolumn{2}{c|}{$\# 2$} & \multicolumn{2}{c|}{$\# 3$} \\
\hline Criterion & Rank & $\begin{array}{c}\text { ROD } \\
\text { weight }\end{array}$ & Rank & $\begin{array}{c}\text { ROD } \\
\text { weight }\end{array}$ & Rank & $\begin{array}{c}\text { ROD } \\
\text { weight }\end{array}$ & Rank & $\begin{array}{c}\text { ROD } \\
\text { weight }\end{array}$ & Rank & $\begin{array}{c}\text { ROD } \\
\text { weight }\end{array}$ \\
\hline C1 & $\mathbf{2}$ & $\mathbf{0 . 2 4}$ & 1 & 0.30 & 1 & 0.30 & 2 & 0.24 & 6 & 0.04 \\
\hline C2 & $\mathbf{3}$ & $\mathbf{0 . 1 9}$ & 3 & 0.19 & 3 & 0.19 & 4 & 0.14 & 3 & 0.19 \\
\hline C3 & $\mathbf{6}$ & $\mathbf{0 . 0 4}$ & 5 & 0.09 & 5 & 0.09 & 5 & 0.09 & 5 & 0.09 \\
\hline C4 & $\mathbf{1}$ & $\mathbf{0 . 3 0}$ & 2 & 0.24 & 2 & 0.24 & 1 & 0.30 & 2 & 0.24 \\
\hline C5 & $\mathbf{5}$ & $\mathbf{0 . 0 9}$ & 4 & 0.14 & 4 & 0.14 & 3 & 0.19 & 4 & 0.14 \\
\hline C6 & $\mathbf{4}$ & $\mathbf{0 . 1 4}$ & 6 & 0.04 & 6 & 0.04 & 6 & 0.04 & 1 & 0.30 \\
\hline
\end{tabular}

[Table 8 . The rankings of the criteria assigned with ROD weights]

The information fed into the DSS was aggregated using the multiplicative value function structure to obtain the resulting total scores for each alternative. The results are shown in Table 9 with alternative 3 as the most attractive, and alternative 2 as the second most attractive, while alternative 1 only achieved a very low score.

\begin{tabular}{|l|r|r|r|r|r|}
\hline & Common & \#1 & \#2 & \#3 & \#4 \\
\hline Alt. 1 & 0.006 & 0.005 & 0.005 & 0.005 & 0.003 \\
\hline Alt. 2 & 0.311 & 0.415 & 0.415 & 0.357 & 0.136 \\
\hline Alt. 3 & 0.684 & 0.580 & 0.580 & 0.638 & 0.861 \\
\hline
\end{tabular}

[Table 9: Total scores for the alternatives using the different weight sets] 
Table 9 both shows the common agreed ranking of the criteria, i.e. the criteria weights, and the individual rankings. Three of the rankings had the socio-economic robustness criterion as the most important criterion, but one ranking (\#4) had the criterion ranked as the least important criterion. The argument for the low priority of this criterion was that all of the alternatives were socio-economically feasible and, therefore, the criterion seemed redundant to the participant (\#4). It is worth noticing that even though the participants had very different perspectives on the weighting of criteria the overall ranking of the alternatives remains unchanged. Only in a state where $\mathrm{C} 1$ and $\mathrm{C} 3$ are assigned with very dominating weights ( 0.6 and 0.2 respectively) a shift takes place from alternative 3 to alternative 2 as the most preferred. Thus the results of the DSS and the decision conference are rather robust towards changes. In cases where the results are more close to each other a more detailed sensitivity analysis should be conducted.

\subsection{Final output from the EM-DSS model}

The EM-DSS model as depicted in Figure 1 encompasses a varying set of methodologies and therefore different output values from the assessment case. Table 10 have accumulated the results in terms of feasibility and thereby ranking of the three alternatives from the $\mathrm{HH}$ Connection.

\begin{tabular}{|l|r|r|r|r|}
\hline \multirow{2}{*}{ Alternatives } & \multicolumn{2}{|c|}{ CBA } & \multirow{2}{*}{ FRA } & \multirow{2}{*}{ MCDA } \\
\cline { 2 - 5 } & BCR & NPV & $27 \%$ & 0.006 (rank 3) \\
\hline $\begin{array}{l}\text { Alternative 1 } \\
(\mathrm{CC}: 9,500 \text { mio DKK) }\end{array}$ & 1.23 & 2,657 & $77 \%$ & 0.311 (rank 2) \\
\hline $\begin{array}{l}\text { Alternative 2 } \\
(\mathrm{CC}: \text { 24,500 mio DKK) }\end{array}$ & 2.38 & 40,506 & & \\
\hline $\begin{array}{l}\text { Alternative 3 } \\
(\mathrm{CC}: 32,500 \text { mio DKK) }\end{array}$ & 1.99 & 38,518 & $69 \%$ & 0.684 (rank 1) \\
\hline
\end{tabular}

[Table 10. Final result from the EM-DSS model]

Evidently, from Table 10 Alternative 1 can be dismissed from the analysis with poor results both from the MCDA and FRA where only $27 \%$ of the iterations return a feasible BCR. Alternative 2 and 3 however, should undergo further scrutiny since the two are very close to each other from the CBA and FRA. Furthermore, from the MCDA exploration Alternative 3 actually outrank 
Alternative 2 in performance; thus, including non-monetary impacts in the evaluation scheme actually produced a shift between alternatives that were not capture in the CBA/FRA analyses.

\section{DISCUSSION}

The presented modelling framework attempts to encompass a wider set of criteria in transport planning than a traditional CBA. Strategic and sustainable transport planning necessitates a broad DSS that is capable to take into account and to assess the multiple and often conflicting criteria and objectives which are difficult to measure in monetary terms. Thus, the use of MCDA provides the opportunity for the decision-makers and stakeholders to assess how the alternatives perform under each criterion and assign them with values enabling a ranking of alternatives. By selecting appropriate criteria it becomes possible to express sustainability in operational terms for actual decision support.

The case study shows that it is possible to take into account a wide range of criteria of an economic, a social, and an environmental character in the same DSS. However, the EM framework contains not only a multi-disciplinary, but also a multi-participatory DSS. The decision conference approach is proposed as the process for structuring the decision process and providing input to the EM-DSS, where all relevant stakeholders can participate and influence the results. An important aspect in this context is the documentation of the assessments and choices made along the way. This is especially the case if the outcome of the decision conference is to be used for implementation of projects or policies and thereby has to be justified to third parties (e.g. the public) where thorough and transparent argumentation is needed. In this respect an assessment protocol can be very useful to record the rationale of the statements made during the five steps of the examination process. If inconsistencies occur in the assessments the protocol can be helpful to clear out misunderstandings or errors, and corrections can be made effectively using the recorded rationale. Moreover, the protocol can include notes about possible disagreements in the group with regard to the assessments and how these were dealt with. A proper documentation of the decision conference can be very helpful both with regard to the conference itself but also when the outcome has to be justified. The protocol should therefore be seen as an integrated part of the decision conference approach. 
The inclusion of economic criteria is inevitable and indisputable in the context of transport infrastructure appraisal. During the last century almost all Western countries have developed policies and manuals within this topic area. One main issue remaining is the treatment and justification of uncertainties and risks as the socio-economic analysis progresses. A key strength in the EM framework is the inclusion of such a module - which can both stand-alone or act as input to the final analysis through a criterion in the MCDA. Effort must, however, be made in future data collection in order to maintain and verify the inaccuracies in cost and demand estimations for the UPD. It is clearly, not an exhausted database system from which subreference classes needs to be supplemented in order to perform a reliable and current data fit.

The framework, however, also has limitations. The final result from the DSS is not a rate that gives an indication of the 'value for money' such as e.g. the BCR. Instead the result is expressed as a relative score that based on a selection of criteria indicates the attractiveness of the alternatives under consideration compared to each other. The economic argument in terms of the costs is a part of one criterion, but this is only set in relation to the conventional CBA impacts which can be monetised, not the remaining criteria that cannot be monetised. In that sense one may argue that a project with high construction costs also is more likely to obtain high scores in the MCDA than a cheaper project trying to solve the same issue. Therefore the result could seem to be given already before commencing the assessments. However, in many cases an expensive project will perform worse in the CBA than the cheaper project, thereby making the CBA and MCDA results respectively contradicting. The final result will thus depend on the trade-off between the CBA and MCDA; that is 'how much should the monetary impacts account for compared to the more strategic criteria'. This trade-off is expressed by the weight assigned to the criterion that contains the CBA/FRA, which for the present case is $\mathrm{C} 1$.

For the presented case the weight of $\mathrm{C} 1$ is set to be rather low ( 0.24 for the common agreed weights), which means that emphasis has been put on the strategic criteria (maybe inspired by a more sustainable way of thinking). Traditionally, dealing with a large infrastructure investment it is, however, expected that the economic gain plays the most significant role. If this is the case and the weight for $\mathrm{C} 1$ changed to approximately 0.6 a shift in terms of the most preferred alternative will also occur. Hence the final decision is sensitive towards the weighting of this specific criterion in the present case. This is useful information for the decision-makers as it is 
pointed out where an extra effort needs to be put in order to make the best possible decision. If on the other hand the final result is robust towards changes in the criteria weights the result simply confirms what the CBA/FRA showed. This is also valuable information in the policy making when the decision needs to be justified, as it can be argued that a wider set of decision criteria has been taken into account in the process.

\section{CONCLUSION}

This paper shows that it is possible to perform a composite appraisal consisting of both CBA and MCDA in the EM-DSS. The overall EM framework does not only include a multi-disciplinary, but as importantly also a multi-participatory DSS as both stakeholders and decision-makers should be involved during the appraisal. The setup of the decision conference should depend on the involved participants, but more importantly be based upon the decision problem to be investigated. Therefore, a major obstacle is the ability to select appropriate methodological approaches that provide a theoretically approved course of action while at the same time maintain its transparency and applicability.

A main concern within the EcoMobility project (and within transport planning in general) is to identify effective means for promoting sustainable transport planning in the Oresund region. This complex challenge can be met as concerns appraisal methodology with the multi-faceted EMDSS, which involves feasibility risk assessment on the socio-economic part of the decision problem, and MCDA to embrace various and often conflicting criteria. To optimise the use of the EM-DSS customised decision conferences become essential where the engagement of stakeholders and their different preferences provide a common platform for understanding a decision problem and for seeking out the most attractive decision alternative.

The MCDA toolbox of the EM-DSS presents only a small selection of techniques that are available within the area. Other techniques not mentioned here might be valuable to include in the toolbox in the future as supplements to the existing. The types of decisions that need to be made may change in the future, and the techniques in the toolbox will need to adapt to such a new situation. However, it is assumed that the existing techniques are able to cover most decision situations within the transport area under the present circumstances. 
Overall, the EM modelling framework provides a new, theoretically sound, and at the same time, practical and effective decision support tool for sustainable transport planning and policy making. Generally, the framework consisting of the proposed examination process and the EMDSS can be refined based on more practical applications and new studies of various assessment problems in transport planning. In this respect the framework set out in this paper is seen as a suitable platform.

\section{REFERENCES}

Banister, D. (2008) The sustainable mobility paradigm. Transport Policy, 15, 73-80.

Banister, D. and Berechman, J. (2000) Transport Investment and Economic Development. UCL Press, London.

Barfod, M.B. (2012a) Optimising Transport Decision Making using Customised Decision Models and Decision Conferences. PhD Thesis, Technical University of Denmark, Denmark.

Barfod, M.B. (2012b) An MCDA approach for the selection of bike projects based on structuring and appraising activities. European Journal of Operational Research, 218, 810-818.

Barfod, M.B., Salling, K.B. and Leleur, S. (2011) Composite decision support by combining cost-benefit and multi-criteria decision analysis. Decision Support Systems, 51, 167-175.

Belton, V. and Stewart, T.J. (2002) Multi Criteria Decision Analysis: An Integrated Approach. Kluwer Academic Publishers, London.

Beukers, E., Bertolini, L. and Te Brömmelstroet, M. (2012) Why Cost Benefit Analysis is perceived as a problematic tool for assessment of transport plans: A Process Perspective. Transportation Research Part A, 46, 68-78.

Cantarelli, C. C., Flyvbjerg, B., van Wee, B. and Molin, E. J. E. (2010). Cost overruns in largescale transportation infrastructure projects: Which explanations can be given. European Journal of Transport Infrastructure Research, 10 (1), pp. 5-18.

Danish Ministry of Transport (2003) Manual for Socio Economic Appraisal: Applied Methodology in the Transport Sector (in Danish). Danish Ministry of Transport, Copenhagen. 
Edwards, W., Miles, R.F. and von Winterfeldt, D. (2007) Advances in Decision Analysis - From Foundations to Applications. Cambridge University Press, USA.

Eliasson, J. and Fosgerau, M. (2013). Cost overruns and demand shortfalls - Deception or selection? Transportation Research Part B: Methodological, Vol. 57 (2013), pp. 105-113.

EUNET/SASI (2001) Final Report - Executive Summary. 4th RTD Framework Programme of the European Commission.

Flyvbjerg, B., Skamris, M.K. and Buhl, S.L., (2003). How common and how large are cost overruns in transport infrastructure projects? Transport Reviews, 23 (1), pp. 71-88.

Flyvbjerg, B. and COWI (2004). Procedures for dealing with Optimism Bias in Transport Planning. Guidance Document prepared for the British Department for Transport, UK.

Flyvbjerg, B. (2007). Megaproject Policy and Planning: Problems, Causes, Cures. Doctoral Dissertation, Faculty of Engineering, Science and Medicine, Aalborg University.

Goodwin, P. and Wright, G. (2009) Decision Analysis for Management Judgment. Fourth ed., John Wiley \& Sons Ltd, UK.

Gühnemann, A., Laird, J.J. and Pearman, A.D. (2012) Combining cost-benefit and multi-criteria analysis to prioritise a national road infrastructure programme. Transport Policy, 23, 15-24.

Hayashi, Y. and Morisugi, H. (2000) International comparison of background concept and methodology of transport project appraisal. Transport Policy, 7, 73-88.

Janic, M. (2003) Multi-criteria Evaluation of High-speed Rail, Transrapid Maglev and Air Passenger Transport in Europe. Transportation Planning and Technology, 26, 491-512.

Kahneman, D. and Tversky, A. (1979) Prospect Theory: An Analysis of Decision under Risk. Econometrica, 47, 263-291.

Keeney, R.L. and Raiffa, H. (1993) Decisions with Multiple Objectives - Preferences and Value Tradeoffs. Cambridge University Press, UK. 
Larsen, L.A. and Skougaard, B.Z. (2010) Appraisal of Alternatives Concerning a Fixed Link between Elsinore and Helsingborg (in Danish). M.Sc. Thesis, Technical University of Denmark, Denmark.

Leleur, S. (2000) Road Infrastructure Planning - A Decision-Oriented Approach. Polyteknisk Press, Denmark.

Lootsma, F.A. (1992) The REMBRANDT system for multi-criteria decision analysis via pair wise comparisons or direct weighting. Report 92-05, Faculteit der Technische Wiskunde en Informatica, Delft University of Technology.

Mackie, P. and Preston, J. (1998) Twenty-one sources of error and bias in transport project appraisal. Transport Policy, 5, 1-7.

Nicolaisen, M.S. (2012) Forecasts: Fact or Fiction - Uncertainty and Inaccuracy in Transport Project Evaluation. Ph.D. Thesis, Aalborg University, Denmark.

Næss, P., Flyvbjerg, B. and Buhl, S. (2006). Do Road Planners Produce More 'Honest Numbers' than Rail Planners? An Analysis of Accuracy in Road-traffic Forecasts in Cities versus Peripheral Regions. Transport Reviews, Vol. 26 (5), pp. 537-555.

Olson, D.L., Fliedner, G. and Currie, K. (1995) Comparison of the REMBRANDT system with analytic hierarchy process. European Journal of Operational Research, 82, 522-539.

Oresundsbro Konsortiet (2010) 10 years: The Øresund Bridge and Its Region. Copenhagen, Denmark.

Phillips, L.D. (2007) Decision conferencing. Advances in Decision Analysis - From Foundations to Applications eds W. Edwards, R.F. Miles and D. von Winterfeldt, pp. 375-399. Cambridge University Press, USA.

Phillips, L.D. (1984) A theory of requisite decision models. Acta Psychologica, 56, 29-48.

Phillips, L.D. and Bane e Costa, C.A. (2007) Transparent Prioritization, Budgeting and Resource Allocation with Multi-Criteria Decision Analysis and Decision Conferencing. Annals of Operational Research, 154, 51-68. 
Roberts, R. and Goodwin, P. (2002) Weight approximations in multi-attribute decision models. Journal of Multi-Criteria Decision Analysis, 11, 291-303.

Saaty, T.L. (1977) Scenarios and priorities in transport planning: Application to the Sudan. Transport Research, 11, 343-350.

Salling, K.B. (2008) Assessment of Transport Projects - Risk Analysis and Decision Support. PhD Thesis, Technical University of Denmark, Denmark.

Salling, K.B. and Leleur, S. (2012) Modelling of Transport Project Uncertainties: Feasibility Risk Assessment and Scenario Analysis. European Journal of Transport Infrastructure Research, 12, 21-38.

Salling, K.B. and Banister, D. (2009) Assessment of large transport infrastructure projects: the CBA-DK model. Transportation Research Part A, 43, 800-813.

Salling, K.B., Leleur, S. and Jensen, A.V. (2007) Modelling Decision Support and Uncertainty for Large Transport Infrastructure Projects: The CLG-DSS model of the Øresund Fixed Link. Decision Support Systems, 43, 1539-1547.

Sayers, T.M., Jessop, A.T. and Hills, P.J. (2003) Multi-criteria evaluation of transport options flexible, transparent and user-friendly. Transport Policy, 10, 95-105.

Tsamboulas, D.A. (2007) A tool for prioritizing multinational transport infrastructure investments. Transport Policy, 14, 11-26.

Tsamboulas, D.A. and Mikroudis, G.K. (2006) TRANS-POL: A mediator between transportation models and decision makers' policies. Decision Support Systems, 42, 879-897.

Van Exel, J., Rienstra, S., Gommers, M., Pearman, A. and Tsamboulas, D. (2002) EU involvement in TEN development: network effects and European value added. Transport Policy, 9, 299-311.

Vose, D. (2008) Risk Analysis - A quantitative guide. Third edition, John wiley \& Sons Ltd., UK. 
Vreeker, R., Nijkamp, P. and Welle, C.T. (2002) A multicriteria decision support methodology for evaluating airport expansion plans. Transportation Research Part D, 7, 27-47.

Wright, S., Nelson, J.D., Cooper, J.M. and Murphy, S. (2009). An evaluation of the transport to employment (T2E) scheme in Highland Scotland using social return on investment (SROI). Journal of Transport Geography, 17, 457-467.

Von Winterfeldt, D. and Edwards, W. (1986) Decision Analysis and Behavioural Research. Cambridge University Press, USA. 